\title{
Engagement in Practice: Some Do's and Don'ts in Partnership Development for a Successful Humanitarian Engineering Project.
}

Shiyin Lim, Santa Clara University

Sydney Thompson, Santa Clara University

I am a senior mechanical engineering student at Santa Clara University, with a passion for implementing social justice through engineering.

Dr. Tonya Lynn Nilsson P.E., Santa Clara University

Tonya Nilsson is a Senior Lecturer in Civil Engineering at Santa Clara University (SCU), where she regularly facilitates pedagogical training for other faculty. Prior to joining SCU, Tonya was an Associate Professor at CSU - Chico. 


\section{Engagement in Practice: The Do's and Don'ts in Partnership Development for a Successful Humanitarian Engineering Project.}

\section{Introduction}

Humanitarian engineering projects are increasingly being used in engineering education as a way to teach sustainable development, involve students in a hands-on project, raise student social awareness and engage underrepresented groups in engineering. Advocates of these projects laud the experience and engineering growth gained by participating engineering students [1]. But these programs face criticism when student experience is placed above project effectiveness and community impact [2]. The literature is full of examples of humanitarian engineering and sustainable development projects that did not work because cultural aspects, social considerations and local knowledge were not considered [3], [4].

Best practices in community development recommend a human-centered design or a capability approach, which both consider the social aspects and the user's ability. Engineers are trained to be excellent problems-solvers but rarely receive training in the social aspects required to develop the empathy necessary to create a human-centered design. As a result, solutions are often useoriented and do not include the human-centered design components required for successful implementation [5] - [8]. Empathy gathering and human-centered design have been recommended for both humanitarian engineering courses and engineering curricula in general but, to date, have not been incorporated widely in engineering curricula [4], [9], [10]. This challenges any extra-curricular, volunteer-group to reliably and consistently incorporate this mindset into a membership that changes yearly.

The Santa Clara University's Engineers Without Borders Student Chapter, EWB-SCU, realized the need for a human-centered design approach through a series of project failures and determined it was critical that all team members learn and practice human-centered design thinking (HCDT). This resulted in the development of a unique sub-team responsible for engaging and preparing volunteer members in the human-centered design approach and providing technical and cultural education to both our members and our community partners. This paper provides a case study of three key interactions between our university and our community partners, with the final interaction highlighting how one university undergraduate group effectively incorporated HCDT into their humanitarian engineering project. The paper includes examples of EWB-SCU's past failures and a recent success to support the case studies and offers lessons learned as Do's and Don'ts. Background on the chapter and the relationship with the community will be established, followed by a synopsis of the project evolution and lessons learned during years of collaboration.

\section{Background}

The Santa Clara University chapter of Engineers Without Borders is a student led organization composed entirely of undergraduate engineering students. Its mission is to apply technical knowledge to solve the world's most pressing problems, currently with the Roof Tile Making $\mathrm{CO}-\mathrm{OP}$ of Abisungaye Gaseke in rural Nyange, Rwanda. EWB-SCU officially partnered with the Nyange Tile Making CO-OP during the summer of 2016. However, EWB-SCU was initially connected to the CO-OP in early fall of 2014. The connection flourished in large part due to the partnering NGO: People In Community Organizing (PICO)-Rwanda. PICO-Rwanda regularly 
works within the community, building a relationship of trust with the community that EWB-SCU has relied upon to build our partnership quickly. PICO-Rwanda has provided excellent translators to improve in-country interactions and have facilitated communication with the COOP during the academic year. It should be noted that PICO is currently in the process of changing their name to Faith In Action International.

\section{Case Study Part 1 - Problem Definition via Skype}

While traveling in Africa during the summer of 2014, a faculty member from SCU was taken by PICO-Rwanda to visit a cooperative, predominantly comprised of women, who were making clay roof tiles by hand using smooth sticks to roll clay into a tile mold. The process, similar to rolling cookie dough, was very physical due to the high stiffness of the local clay. PICO-Rwanda asked for help and the faculty member suggested that engineering students from SCU could create a mechanical press that would push the clay into the tile molds. In October of 2014, a group of EWB affiliated students agreed to take on the project. An engineering faculty member not affiliated with EWB requested to mentor the students and proceeded to direct their efforts. Neither the students nor the faculty member had any training in HCDT and the project was conducted separately from EWB-SCU.

A Skype call was arranged where the students, through translators, requested the dimensions of a tile. During the call, the community also expressed a need for a clay mixer, which the mentoring faculty member indicated the SCU students could also provide. The intent was to deliver both the tile press and the clay mixer during the summer of 2015, however the clay mixer was not completed until the summer of 2016. Late summer 2015, four students and a third faculty member who had not worked on the project, traveled to Rwanda with the tile press, shown in Figure 1 in the Appendix. The press's first in-country test in the summer of 2015 showed it would not meet the CO-OP's needs. The press did not account for the high stiffness of the clay, the speed at which the clay needed to be pressed, and the physical ability of the Nyange people. In addition, the press was designed to be used with molds based on the dimensions provided during the Skype call, which turned out to be the finished tile dimensions after curving and firing. The molds for the wet clay were too small. The original press was left with a technical institute in Rwanda where new molds were created and the press's table was reinforced to mitigate deflection and bowing. The community received the improved system during the summer of 2016, but the pressing mechanism still proved too weak and slow for the stiffness of the clay and the press was never used by the CO-OP to produce their roof tile product.

While in country summer of 2015, the travelers did not collect any assessment or design data for the yet to be delivered clay mixer. However, one student member of the travel team, was motivated to complete the mixer and, with a small team of students and the same engineering faculty mentor, continued working on the project during the 2015-16 school year. The design included taking a U.S. made, stainless steel, clay mixer and replacing the motor with a geared system that could be driven by a human-powered bicycle as shown in Appendix Figure 2.

During the same academic year (2015-16), the EWB-SCU student chapter, in partnership with PICO-Rwanda, officially partnered with the CO-OP through the established Engineers Without Borders framework. This allowed the EWB-SCU students to travel during the summer of 2016 under the EWB framework to meet the community, complete tests on the clay, conduct pre- 
project assessments to determine the CO-OP's most pressing needs, observe the entire tile making process and deliver the clay mixer. Due to unexpected customs challenges, the mixer, which was too heavy to send as luggage, was not released to the team until two days before the end of the trip. The reduced time frame resulted in the team assembling the mixer, demonstrating its use and training the community to disassemble and reassemble the mixer all on the same day.

The community was initially enthusiastic and excited about the mixer but within three months of returning home, the team learned the mixer was not being used. Riding the bicycle, which had been geared to be very easy for the SCU students, was significantly more challenging for the malnourished CO-OP members. Also, clay mixers are specifically designed to hydrate dry clay with added water. However, fifty percent or more of the year, the community harvests already wet clay. It was later learned that the CO-OP actually wanted a machine to "wedge" or knead the clay to make it smooth for rolling and pressing. In the U.S., this type of machine is called a pug mill. Challenges in translation and the lack of in-person communication and process observations led to the community receiving a second machine that offers them little value.

\section{Case Study Part 2 - A Use-Centered Solution}

Based on interview data and tile-making observations collected during summer 2016, the EWBSCU team implemented a second version of the tile press during summer 2017. The new press, shown in Figure 3 in the Appendix, was completely redesigned to impart eight times the force as the 2015 press with significantly less physical effort from the user. The women of the CO-OP enthusiastically received the press and were excited by how easily they could press a highquality, dense tile. However, six months after implementation, EWB-SCU learned the press was no longer in regular use. Further investigation determined the CO-OP members prefer to work communally on the same task side-by-side. The new tile press can only be operated by one person at a time and failed to meet the communal culture of tile making for CO-OP. The CO-OP members use the press to make sample tiles to demonstrate the top quality tile they can produce but their day to day tiles are still made by a group of members rolling out clay.

In summary, the second tile press was successful in meeting engineering standards, but it was the definition of use-centered instead of human-centered and was ultimately unsuccessful. Even though interviews and in-country observations had garnered information on the tile making process, EWB - SCU had mistakenly focused on how the tiles were made, and not how the COOP made the tiles with one another. This was further reinforced in summer 2018 when the EWBSCU team found the community resistant to incorporating the press in an assembly line process, as this disrupted the cultural norm of working on the same task side-by-side. Determining how the community would use the press, beyond the simple mechanics, required an entirely different set of questions than the engineering students were not trained to ask.

\section{Case Study Part 3 - A Human Centered Design Approach}

Feedback from the volunteer students who worked on the original tile press and the humanpowered clay mixer indicated it was difficult for students who had never traveled to Rwanda to maintain a sense of urgency regarding project tasks during the academic year. Non-travelers had no familiarity with the CO-OP and the CO-OP members to motivate their efforts. To develop this connection, the EWB leadership proposed the creation of a unique sub-team called the Education Ministry, which actively works to educate non-traveling members of the organization. By 
contextualizing the engineering work, the education team helps maintain a sense of urgency and an awareness of the reality of our community members' lives. Presentations about the Rwandan genocide, profiles of our community in general, and detailed profiles of community members were introduced to general meetings.

The Education Ministry's efforts vastly improved EWB-SCU's cultural connection but the summer 2017 project, the improved tile press, still ended with a use-centered design. This brought home the need for human-centered design approaches. Education Ministers took courses on HCDT outside the School of Engineering and began holding HCDT "sprints": short HCDT practice exercises, for the membership. The Education Ministry took on the responsibility of training members in techniques for building empathy and human-centered approaches and they now attend the engineering design meetings as observers to ensure the design is user-focused instead of use-focused.

This approach was practiced during the design and implementation of the 2017-2018 project to address the community's challenge of carrying clay from the harvest site to the tile-making site. Various transport options that allowed for the CO-OP to work together were considered and shared with the community via our PICO-Rwanda partners early in the design process. A battery powered cart, shown in Appendix Figure 4, with the ability to carry up to 80 kilograms of clay was preferred by the CO-OP. At the date of writing, the cart is still in use and the EWB-SCU team is working on an improved version that incorporates feedback from the community and is less reliant on parts made in the U.S.

\section{Discussion}

The detailed case-study of EWB-SCU highlights a number of 'don'ts' in humanitarian engineering. Through our failures we have learned a number of 'do's' in terms of partnership development, project development, and project longevity.

\section{Partnership Development}

An in-country NGO that is already working with the community is critical to bridge the cultural, technical, and communication gap. An introduction to the community from a trusted NGO will reduce early distrust of foreigners. The NGO should understand the local culture and can provide guidance on design decisions. Importantly, the NGO can also facilitate regular communication with the partner community during the academic year.

Our own community members did not initially understand the concept of a 'college club' and did not connect new travelers to past visitors. Having at least two returning travelers each year fosters a sense of continuity, as does starting each visit with a reminder of who we are, why we are there, and how the teams are connected. Bringing group photos from previous years greatly supports this. Our efforts are working; last summer the Nyange Tile Making CO-OP indicated seeing the EWB-SCU chapter return year after year with familiar faces encourages them to work hard because they feel constantly supported and loved and remember that their partners are real people, who take the time to think about them at all times of the year.

Lastly, understanding the community partner is the single most effective way student engineers can ensure the success of the partnership and resulting projects. There is always a risk of 
processing new information through your own lens, which typically leads to poor assumptions. This risk is magnified in cross-cultural communication with translators. Whenever possible, watch a process instead of only asking how it is done, ask multiple people the same question, and be aware of leading questions that inhibit honest answers. Never assume you know something, the odds are you are missing information. A 'Do's and Don'ts' table is provided in the Appendix to serve as a quick reference of how to minimize miscommunications and increase community understanding.

\section{Project Development}

Successful humanitarian projects need to take a human-centered design approach, as opposed to a use-centered design focus. For practicing engineers, engineering faculty, and engineering students this may mean a degree of unlearning the constant gravitation towards solution-oriented thinking and, instead, adopting a patient and empathetic lens that centers on the human and social problem instead of the physical problem. Maintain an awareness that the travelers will come with their own preconceptions and the community will have their own set of expectations of the engineering team. There must be serious and extensive conversations about what the community expects and about what the engineering volunteers can realistically provide. For the EWB-SCU students, this takes the form of in-country, face-to-face meetings with community leaders, conversations with the NGO about their interpretations of the community's expectations, and in-country observations of the tile-making process.

\section{Project Longevity}

Designers' expectations on how the equipment will be used should also addressed. Regardless of training and/or instruction manuals, the project will be used in ways that the engineers do not anticipate. By predicting and designing for the unexpected, the long-term sustainability of a project can be improved.

The ability of the community to maintain the project is also key to sustainability. Designing the prototype for easy in-country maintenance allows for the community members to have agency in the maintenance and sustainability of the project, and helps create a sense of ownership that is essential to trust and a fruitful partnership. In order to accomplish this, available parts and ease of maintenance should be considered during assessment trips, and communication with the incountry NGO on available materials should occur before the design process begins.

\section{Summary}

This paper describes the creation of a special subteam, the Education Ministry, that has developed a sustainable approach to support a human-centered mindset in the continually changing student team membership. The Education Ministry develops and maintains presentations for each chapter project and each CO-OP member. These presentations educate new members and travelers about the people we are working for and the past projects, how they work and what the successes and failures were associated with that project. The subteam also offers training in HCDT and regularly assesses Engineering Team efforts to ensure social aspects are considered. Finally, the Education Ministry is an ideal place to engage first-year students, who later develop into a pool of upper division leaders with long-term knowledge of the projects. These students are able to grow with the project and support mentoring of the next batch of firstyear students, creating intentional continuity and increasing project longevity. 
The provided case study highlights the importance of prioritizing the human connection for the success of the project and the health of the relationship between partners. Understanding individuals of the community holistically and listening to their stories allows for the creation of deep connections that motivate and sustain the project. Behind every physical problem there is social explanation that requires a human-centered solution. Creating a human-centered design mindset among the students and the advising faculty supports the development of a cohort of engineers that identify the real problem before jumping to solution.

\section{Bibliography}

[1] B.K. Jaeger \& E.P.M LaRochelle, "EWB2 - Engineers Without Borders: Educationally, a World of Benefits," American Society for Engineering Education National Conference, June 2009

[2] D. LaPorte, E. Kim, \& J. Smith, "An Ethnographic Case Study of an Engineering-to-Help Student Organization”, International Journal for Service Learning in Engineering, Humanitarian Engineering and Social Entrepreneurship, 12(2), 2017, pp. 103-117

[3] J. Schneider, J.A. Leydens \& J. Lucena," Where is 'Community'?: Engineering education and sustainable community development", European Journal of Engineering Education, 33(3), 2018, pp. 307-319,2018 DOI: 10.1080/03043790802088640

[4] J. Lucena, J. Schneider \& J.A. Leydens, Engineering and Sustainable Community Development, Morgan \& Claypool Publisher, 2010

[5] C.L. Dym, A.M. Agogino, O. Eris, D.D. Frey, \& L.J. Leifer, "Engineering design thinking, teaching and learning", Journal of Engineering Education, 94(1), 2005, pp. 103-120

[6] Richard Buchanan, "Human Dignity and Human Rights: Thoughts on the Principles of Human-Centered Design", Design Issues, 17, 2001, pp. 35-39.

[7] I. Oosterlaken, "Design for development: a capability approach", Design Issues, 25(4), 2009, pp. 91-102

[8] D. Nieusma, "Alternative design scholarship: working toward appropriate design", Design Issues, 20(3), pp. 13-24

[9] D.I. Levine, A.M. Agogino, \& M.A. Lesniewski, "Design Thinking in Development Engineering" http://best.berkeley.edu/wpcontent/uploads/2015/07/DE Mudd v16 AMA.pdf, retrieved January 26, 2019

[10] S.D. Sheppard, K. Macatangay, A. Colby \& W.M. Sullivan, Educating engineers: designing for the future of the field, Jossey-Bass Publishers, 2008 


\section{Appendix}

Table 1. Suggestions for minimizing cross-cultural miscommunication.

\begin{tabular}{|c|c|c|c|}
\hline Activity & Do & Don't & Why \\
\hline \multirow{5}{*}{$\begin{array}{l}\text { Interviewing } \\
\text { Community Members }\end{array}$} & $\begin{array}{l}\text { Vary your } \\
\text { interviewees. }\end{array}$ & $\begin{array}{l}\text { Single out } \\
\text { interviewees based on } \\
\text { status, gender, or age. }\end{array}$ & $\begin{array}{l}\text { Interview data is } \\
\text { easily skewed. }\end{array}$ \\
\hline & $\begin{array}{l}\text { Ask open ended } \\
\text { questions. }\end{array}$ & $\begin{array}{l}\text { Ask yes or no } \\
\text { questions about their } \\
\text { lives. }\end{array}$ & $\begin{array}{l}\text { It's easy to impose } \\
\text { bias on the answers of } \\
\text { the community } \\
\text { members. }\end{array}$ \\
\hline & $\begin{array}{l}\text { Ask two or three } \\
\text { people the same } \\
\text { question. }\end{array}$ & $\begin{array}{l}\text { Take one answer to } \\
\text { be the truth. }\end{array}$ & $\begin{array}{l}\text { Answers often } \\
\text { conflict with each } \\
\text { other, regardless of } \\
\text { how simple the } \\
\text { question. }\end{array}$ \\
\hline & $\begin{array}{l}\text { Switch between } \\
\text { individual and group } \\
\text { interviews. }\end{array}$ & $\begin{array}{l}\text { Only interview one- } \\
\text { on-one. }\end{array}$ & $\begin{array}{l}\text { Sometimes people are } \\
\text { more willing to talk } \\
\text { in a group setting. }\end{array}$ \\
\hline & $\begin{array}{l}\text { Pay attention to body } \\
\text { language and physical } \\
\text { cues. }\end{array}$ & $\begin{array}{l}\text { Only trust the } \\
\text { translator to convey } \\
\text { the message. }\end{array}$ & $\begin{array}{l}\text { Ideas may literally be } \\
\text { lost in translation. }\end{array}$ \\
\hline \multirow[t]{3}{*}{ Proposing Plans } & $\begin{array}{l}\text { Propose only what is } \\
\text { realistic. }\end{array}$ & $\begin{array}{l}\text { Propose a non- } \\
\text { feasible idea. }\end{array}$ & $\begin{array}{l}\text { You may } \\
\text { inadvertently promise } \\
\text { the community } \\
\text { something that can't } \\
\text { be delivered. }\end{array}$ \\
\hline & Propose a single idea. & Propose $2-3$ options & $\begin{array}{l}\text { Choosing the project } \\
\text { or the design option } \\
\text { will give the } \\
\text { community more } \\
\text { responsibility and } \\
\text { ownership. }\end{array}$ \\
\hline & $\begin{array}{l}\text { Inadvertently promise } \\
\text { multiple projects at } \\
\text { one time. }\end{array}$ & $\begin{array}{l}\text { Be very specific with } \\
\text { what you will and } \\
\text { will not do. }\end{array}$ & $\begin{array}{l}\text { Indicating you can, } \\
\text { i.e. "have the ability" } \\
\text { to do a project can } \\
\text { easily be translated as } \\
\text { you will do a project. }\end{array}$ \\
\hline
\end{tabular}




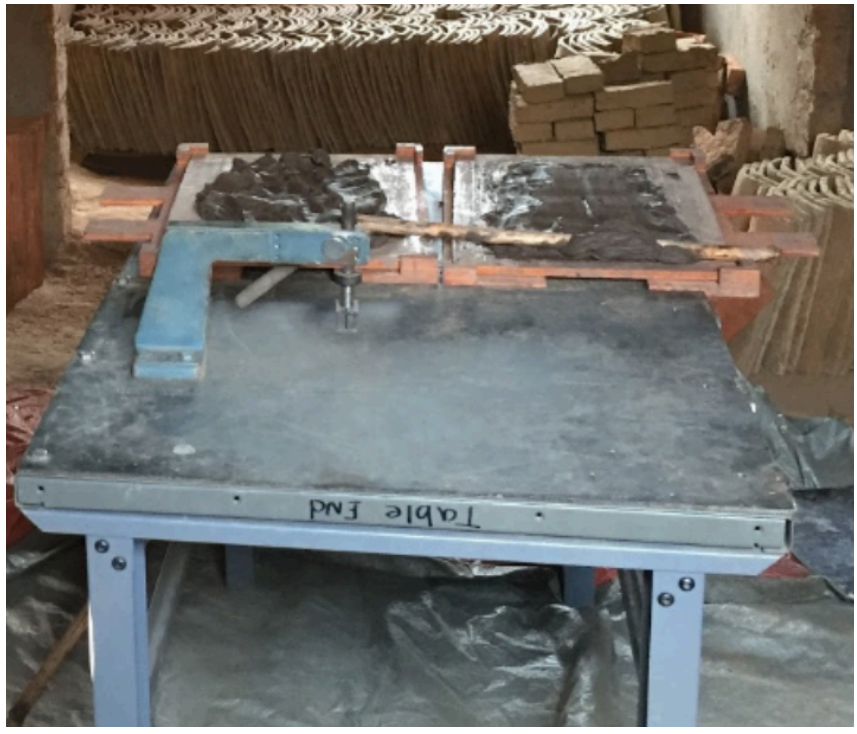

(A)

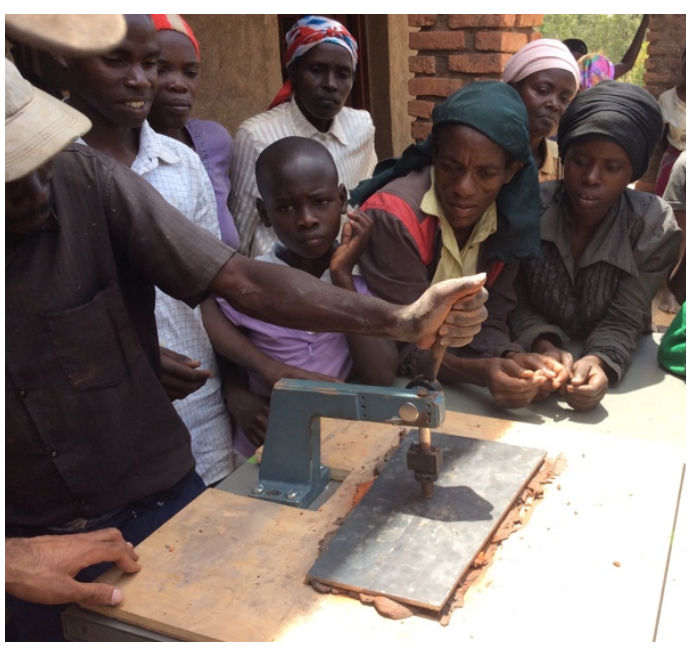

(B)

Figure 1. (A) The original tile press incorporated an arbor press with a prefabricated steel table. Both the table components and the press were brought to Rwanda as traveler's luggage. (B) The original undersized tile mold was integrated into the pictured plywood sheet. The steel plate helps to distribute the arbor press force. The designers of this press had never traveled to Rwanda and had only communicated with the community by Skype.

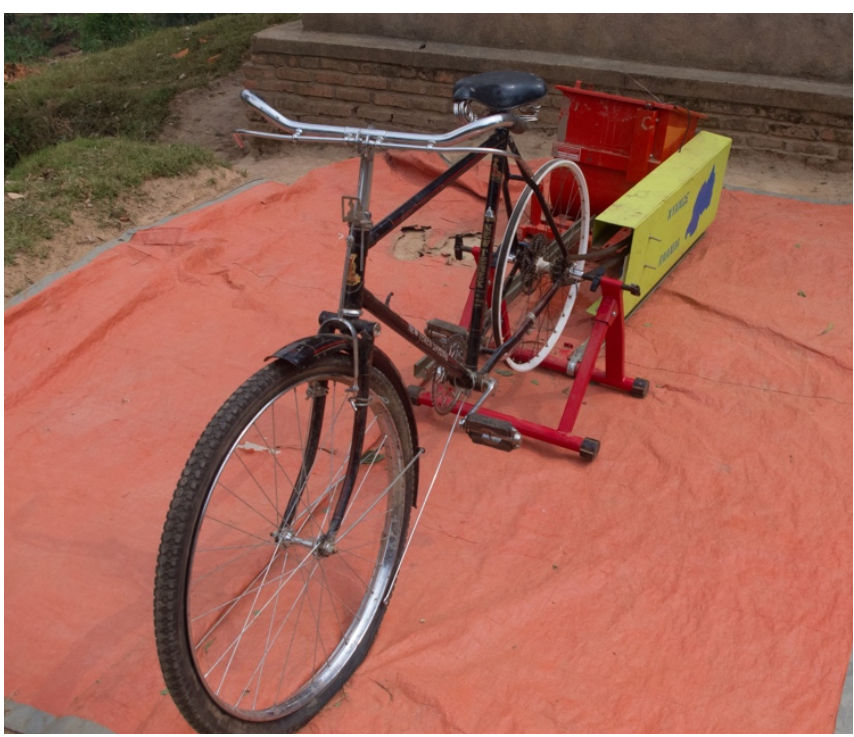

(A)

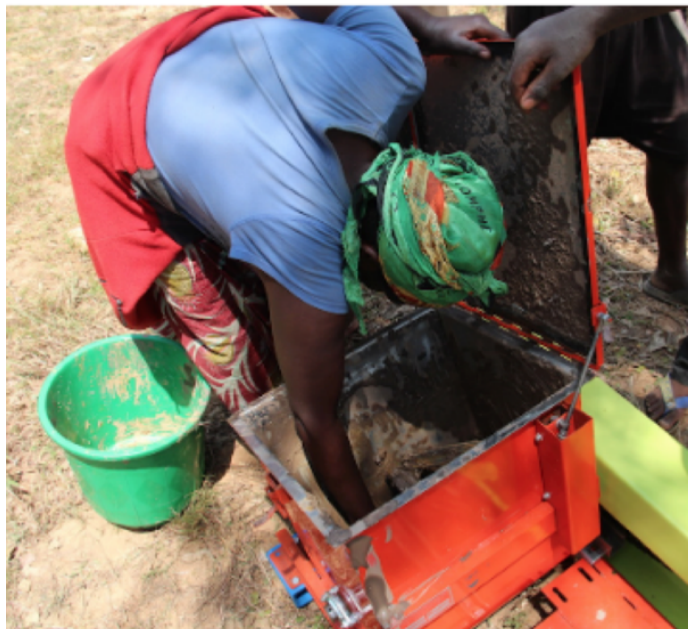

(B)

Figure 2. (A) Bike powered clay mixer. Shown with chain guard covering gear attached to mixer and large motorcycle chain driven by the rear real. The bicycle was purchased in Rwanda. The mixer was shipped to Rwanda and all other parts were sent in cardboard boxes as luggage. (B) The mixer has a capacity of approximately 15 kilograms of clay. The need for a "mixer" was determine during a Skype call with the designers. 


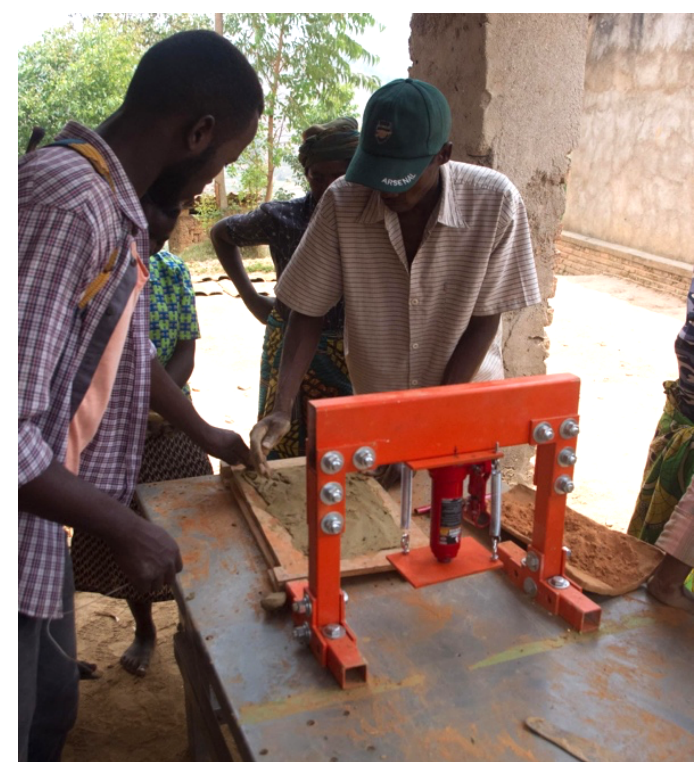

(A)

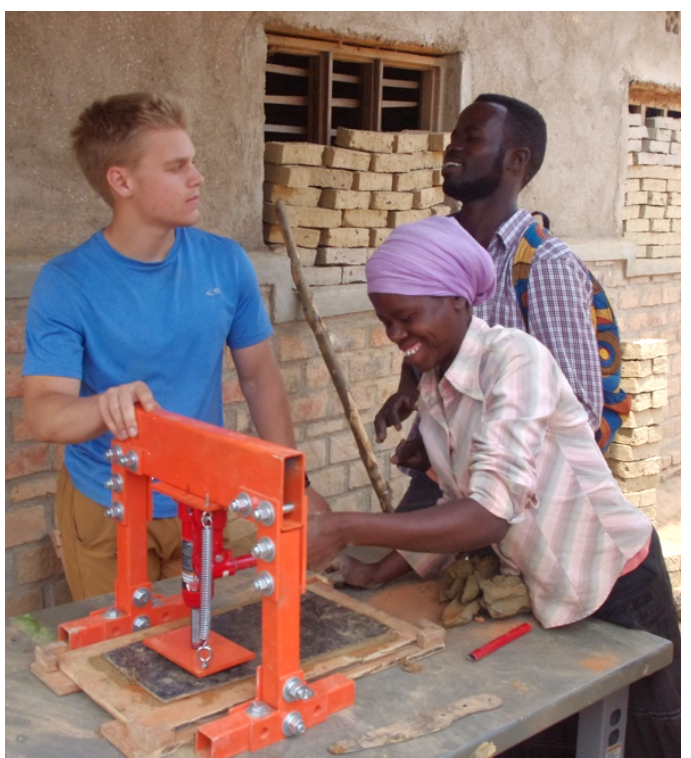

(B)

Figure 3. The second tile press used a hydraulic jack to 4000 pounds force but required little user effort. The press was mounted on the steel table of the original press. All press parts were carried in travelers' luggage. (A) Clay is roughly spread into the clay tile mold. (B) A steel plate is aligned over the mold and distributes the press load over a larger clay area.

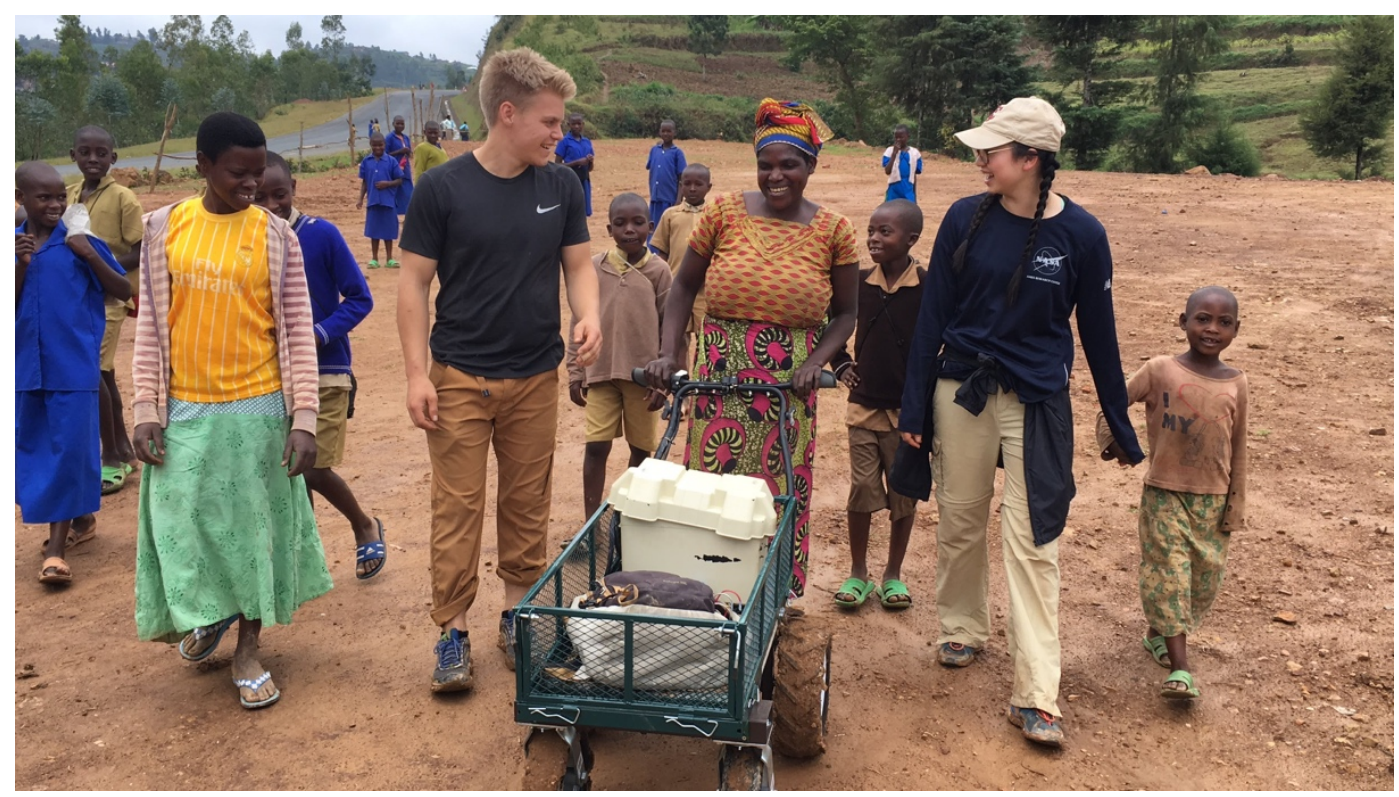

Figure 4: The CO-OP President taking the electric-powered cart for its first test run. The cart has the capacity to carry $80 \mathrm{~kg}$ of clay up steep inclines. The wagon sides fold down for flat packing and the wheel supports and handle are removable. The entire cart was disassembled prior to travel and the parts were sent in luggage. The batteries and solar panels for battery charging were purchased in Rwanda. 